\title{
A prospective observational study of role of epidural in trial of labour after cesarean section in view of maternal and neonatal outcome in a tertiary care hospital
}

\author{
Jothi Sundaram, Divya Vinoth, Malathi Sriram*
}

Department of Obstetrics and Gynecology, Rajaji Government Medical College and Hospital, Madurai, Tamil Nadu, India

Received: 20 February 2020

Revised: 01 March 2020

Accepted: 27 March 2020

\section{*Correspondence:}

Dr. Malathi Sriram,

E-mail: sriram.t6489@gmail.com

Copyright: (C) the author(s), publisher and licensee Medip Academy. This is an open-access article distributed under the terms of the Creative Commons Attribution Non-Commercial License, which permits unrestricted non-commercial use, distribution, and reproduction in any medium, provided the original work is properly cited.

\section{ABSTRACT}

Background: In a well-equipped hospital, trial of vaginal delivery is done in selected cases of previous C-section (CS). Epidural analgesia administration has been proved to be good adjunct in trial of labor after caesarean (TOLAC). Methods: This study is a prospective observational study done in a tertiary care institution in Tamil Nadu from May 2019 to July 2019. 50 cases with previous history of one CS were selected. Single ton pregnancy, previous transverse lower segment cesarean section admitted cases with adequate pelvis with no other co-morbidities were selected. Epidural analgesia was administered once mother was in established labor. TOLAC was continued till satisfactory progress and emergency repeat caesarean was taken in case of Suspected scar dehiscence (SSD) or abnormal fetal heart rate tracings. Quantitative data was expressed in mean and standard deviation. For qualitative data percentage was used.

Results: In 50 cases observed the mean age of the cases was $26 \pm 3.64$ years. TOLAC was successful in 41 (82\%) mothers out of 50. The mode of delivery in 41 TOLAC mothers was found to be forceps in 18 cases (36\%) and ventouse delivery 18 cases $(36 \%)$. Only 9 cases had needed emergency CS (18\%). The major indication for CS in TOLAC was found to be fetal distress in 4 number of cases $(8 \%) .43$ babies delivered were healthy, 6 babies (12\%) admitted in NICU.

Conclusions: With the application of epidural analgesia on attempted vaginal delivery in previous cesarean, vaginal delivery was $82 \%$ cases.

Keywords: Epidural, Trial of labor after caesarean, Vaginal birth after cesarean section

\section{INTRODUCTION}

Women who become pregnant after delivering their first baby by caesarean section often have to make a decision about how to deliver their next baby. Typically, they will be offered the choice of having an elective repeat caesarean section (ERCS) or attempting a vaginal birth after caesarean section (VBAC). ${ }^{1,2}$ Although the World Health Organization has recommended that no more than $15 \%$ of deliveries should be via Cesarean section (CS), there is a continuous uptrend in the incidence of the CS in the developed and developing countries. ${ }^{3-6}$

Epidural analgesia administration has been a good adjunct in Trial of labor after caesarean (TOLAC). ${ }^{7}$

As per Flam Geiger scoring system, the cases were categorized. In 1999 American Congress of Obstetricians (ACOG) stated that in a practice bulletin that a physician who is capable of monitoring labor and performing an 
emergency caesarean delivery be "immediately" available as offered to readily available when women attempt VBAC. ${ }^{8}$

All post-caesarean pregnancies do not require repeat caesarean section and majority of them may have uncomplicated vaginal delivery. ${ }^{9}$ There is a risk of uterine rupture in vaginal birth after caesarean delivery (VBAC) leading to catastrophes which can be avoided by continuous monitoring with prompt intervention. ${ }^{10-13}$ Evidence confirming the safety of TOLAC within proper guidelines has been available for more than years. ${ }^{14-17}$ To control the rising rate of caesarean sections (CSs), vaginal birth after caesarean section (VBAC) is one of the strategies developed. ${ }^{18}$ In a well-equipped hospital, trial of vaginal delivery is done in selected cases of a previous CS. ${ }^{19}$ However wide variation in VBAC rates still exists between hospitals and obstetricians and several factors increase the likelihood of a failed trial, which in turn might lead to increased maternal and perinatal morbidity and mortality rates. In view of this, trial of vaginal delivery in women with post caesarean pregnancy remains controversial and continuous critical audit of the trends is imperative. Women and their relatives should be informed and counselled appropriately regarding the safety and the risk involved in both the modes of delivery. There is paucity of studies regarding role of epidural in TOLAC in Indian sub-continent. Hence, authors tried to analyse maternal and neonatal outcome of the TOLAC as well the success rate of TOLAC with epidural analgesia in our government run tertiary care institute. This study might provide an evidence and guideline for patients and the Obstetricians while making the choice of either TOLAC with epidural analgesia and emergency repeat caesarean section (ERCS).

In this study authors have conducted a prospective observational study of maternal and neonatal outcome in women undergoing TOLAC with epidural analgesia.

\section{METHODS}

This study is a prospective observational study which was done in the department of obstetrics and gynecology, Government Rajaji Hospital, a tertiary care institution in Madurai, Tamil Nadu from May 2019 to July 2019. The average total number of deliveries per month is 1300.50 cases with previous history of one caesarean section were selected. From the admitted antenatal mothers were assessed for a trial of vaginal delivery. Single ton pregnancy, previous transverse lower segment cesarean section cases with adequate pelvis with no other comorbidities were selected and were included in the study after informed written consent.

Cases with previous two or more LSCS, contracted pelvis and cephalopelvic disproportion, previous classical or inverted T-shaped incision on the uterus, and those having other medical or obstetrical complications associated with pregnancy have been excluded from the study. A total of 50 cases that fulfilled the selection criteria were enrolled in the study. Ante natal mothers and their relatives were explained about the advantages of vaginal birth after cesarean. They were also explained about the risk of scar dehiscence and the need for emergency CS, if trial of vaginal delivery failed. Written informed consent was obtained at the time of enrolment in the study. The patients were asked to come for regular antenatal checkups and were advised to plan their delivery in the hospital where the study was conducted. Hematological and serological investigations and obstetric sonography were performed during antenatal visits. The women were advised to get admitted in the ward, two week prior to their expected date of delivery.

After going through the record related to her previous CS, a decision regarding TOLAC was taken by a senior obstetrician in the later weeks of pregnancy or during labor. Induction was done in selected cases through mechanical methods/PGE2 gel according to the Bishop score. The cases selected for TOLAC were monitored carefully during labor by continuous electronic fetal monitoring.

Epidural anesthesia procedure: under strict aseptic precautions, after painting and draping the area epidural needle Tuohy needle 16 or 18 gauge inserted at L2-L5 space identified by loss of resistance technique, then corresponding catheter is inserted and 4-6 cm in addition to epidural space from skin is fixed, then test dose with 3 $\mathrm{ml} 1.5 \%$ lignocaine is given to confirm the correct space, then secure the epidural catheter. Local anesthesia $0.125 \%$ Bupivacaine $10-15 \mathrm{ml}$ is given in patient with true labour pain and cervical dilatation of $4 \mathrm{~cm}$. Top up will be giver for every 90 mins with $0.125 \%$ Bupivacaine $10 \mathrm{cc} .^{20}$

Epidural analgesia was administered once mother was in established labor. Intrapartum continuous monitoring and all patients were monitored with continuous CTG were done by using the standard partograph of the World Health Organization (WHO). Four-hourly internal examinations were performed to assess the progress, and special attention was paid towards the evidence of scar dehiscence or rupture. The trial of labour after cesarean was continued till there was satisfactory progress. Emergency repeat caesarean was taken in case of suspected scar dehiscence or abnormal fetal heart rate (FHR) tracings. Cases with successful VBAC delivery were kept in the hospital for five days and those who required repeat $\mathrm{CS}$ were kept for seven days after the operation. All cases have been given broad-spectrum antibiotics for 7 days.

Quantitative data was expressed in mean and standard deviation. For descriptive statistics frequency and percentage were used and to find out the difference between the proportions, chi square test or Fischer exact test was used, $\mathrm{p}<0.05$ was considered significant. 


\section{RESULTS}

In 50 cases observed the mean age of the cases was $26 \pm 3.64$ years.

\section{Table 1: Previous indication for caesarean section} in TOLAC.

\begin{tabular}{|c|c|c|c|}
\hline \multirow{2}{*}{$\begin{array}{l}\text { Indication for } \\
\text { previous } \\
\text { caesarean }\end{array}$} & \multicolumn{2}{|l|}{ TOLAC } & \multirow[b]{2}{*}{ Total } \\
\hline & VBAC & $\begin{array}{l}\text { Repeat } \\
\text { caesarean }\end{array}$ & \\
\hline Fetal distress & 16 & 2 & 18 \\
\hline $\begin{array}{l}\text { PROM with } \\
\text { fetal distress }\end{array}$ & 5 & 3 & 8 \\
\hline Failed induction & 6 & 1 & 7 \\
\hline Breech & 4 & 0 & 4 \\
\hline CPD & 1 & 1 & 2 \\
\hline $\begin{array}{l}\text { Severe } \\
\text { oligohydramnios }\end{array}$ & 3 & 0 & 3 \\
\hline $\begin{array}{l}\text { Post-dated with } \\
\text { failed Induction }\end{array}$ & 6 & 2 & 8 \\
\hline Total & $41(82 \%)$ & $9(18 \%)$ & $50(100 \%)$ \\
\hline
\end{tabular}

It was observed that in 50 cases with previous caesarean section, the major indications for previous caesarean section (Table 1) was fetal distress in 16 cases, premature rupture of membrane (PROM) in 9 cases (18\%) and Failed induction in 9 cases $(18 \%)$. There were no significant differences among previous indications for caesarean section and trial of labor after caesarean section $(\mathrm{p}>0.05)$.

TOLAC was successful in $41(82 \%)$ mothers out of 50. The mode of delivery in 50 observed cases with previous caesarean section (Table 2) was found to be forceps in 18 cases $(36 \%)$ and ventouse delivery 18 cases (36\%). Only 9 cases had needed emergency caesarean section (18\%).

The major indication for caesarean section (Table 3) in trial of labour (TOLAC) was found to be fetal distress in 4 number of cases (8\%) followed by suspected scar dehiscence in 3 cases $(6 \%)$ and scar rupture 1 cases $(2 \%)$ and failed induction in 1 case $(2 \%)$. Out of 4 cases of fetal distress indicated, only one baby had mild respiratory distress. Other 3 babies were normal. Out of the 3 taken for suspected scar dehiscence, only one patient had scar rupture intra-operatively. Lower uterine segment was intact in other 2 patients.

Table 2: Mode of delivery in TOLAC.

\begin{tabular}{|lll|}
\hline Mode of delivery & No. of cases & Percentage \\
\hline Forceps & 18 & 36 \\
\hline Ventouse & 18 & 36 \\
\hline Vaginal delivery & 5 & 10 \\
\hline Caesarean & 9 & 18 \\
\hline Total & 50 & 100 \\
\hline
\end{tabular}

Table 3: Indication for repeat section in TOLAC.

\begin{tabular}{|lll|}
\hline Indication for caesarean & $\begin{array}{l}\text { No. of } \\
\text { cases }\end{array}$ & Percentage \\
\hline $\begin{array}{l}\text { Abnormal fetal heart rate } \\
\text { tracings }\end{array}$ & 4 & $44 \%$ \\
\hline Suspected scar dehiscence & 3 & $34 \%$ \\
\hline Scar rupture & 1 & $11 \%$ \\
\hline Failed induction & 1 & $11 \%$ \\
\hline Total & 9 & $100 \%$ \\
\hline
\end{tabular}

Out of 50 cases, 9 cases had repeat caesarean indication in which 4 babies had in NICU admission and 1 baby have neonatal mortality. The trend was found to be statistically significant $\mathrm{p}<0.05$ (Table 4). Out of the 50 cases delivered, 43 babies delivered were healthy and handed out to the mother $(86 \%)$, there were 6 babies (12\%) admitted in neonatal intensive care unit (NICU) due to fetal distress (4), preterm with low birth weight (1) and heart disease (1). 1 case of perinatal death (2\%) has been reported in this study (Table 4 ). Out of the 4 cases of abnormal fetal heart rate tracing decided for Emergency LSCS; post-natal evaluation showed that 3 out of 4 babies had no acidosis fetal distress and actually one baby had fetal distress which resolved eventually.

Table 4: Neonatal outcome versus TOLAC.

\begin{tabular}{|c|c|c|c|c|c|}
\hline \multirow{2}{*}{ TOLAC } & \multicolumn{3}{|c|}{ Baby status } & \multirow{2}{*}{ Total } & \multirow{2}{*}{$X^{2}, d f, p$ value } \\
\hline & Healthy & NICU admission & Expired & & \\
\hline VBAC & $39(95 \%)$ & $2(5 \%)$ & 0 & $41(82 \%)$ & \multirow{3}{*}{$16.38,2,0.01$} \\
\hline Repeat caesarean section & $4(44 \%)$ & $4(44 \%)$ & $1(12 \%)$ & $9(18 \%)$ & \\
\hline Total & $43(86 \%)$ & $6(12 \%)$ & $1(2 \%)$ & $50(100 \%)$ & \\
\hline
\end{tabular}

$\mathrm{X} 2$ - Chi square value, $\mathrm{p}<0.05$ trend is statistically important.

\section{DISCUSSION}

Epidural analgesia plays an important role in patient acceptance of trial of labor after prior cesarean delivery. Pre-anesthetic evaluation and counseling should occur early in the patient care. Intrapartum management includes appropriate oral intake and close communication between anesthetist and obstetrician. Epidural analgesia is emerging as safe and significant adjunct for a successful TOLAC. It is essential to counsel patients with 
a history of prior cesarean section, ideally during antenatal period, regarding the benefits and risks of TOLAC, enabling them to make informed choice early and probably bring down the repeat cesarean section rate. Induction is safe in selected cases. Majority of the cases of previous CS done for non-recurrent indication can be delivered safely by the vaginal route, without any major complication to the mother and the newborn, in an institution having facilities for emergency caesarean sections. It has been proved to be a safe alternative to repeat an elective caesarean.

The American college of obstetricians and gynecologists (ACOG) estimated the risk of uterine rupture in women with a previous CS and concluded that the lower segment caesarean scar has a minimum risk $(0.2-1.5 \%)$ of rupture during vaginal delivery. There was no maternal mortality in the present study. Out of total 50 cases enrolled in the study 41 delivered vaginally. While repeat cesarean delivery was carried out in 9 cases. When trial of labour had to be abandoned for various reasons including fetal distress, non-progress and suspected scar dehiscence. 18 babies were born by ventouse extraction and 18 babies by forceps extraction to cut short second stage of labor and poor maternal bearing down due to epidural. The remaining 9 babies were born by emergency CS, following failed trial of labor after cesarean section (TOLAC). Four was performed for fetal distress and the other three were performed for suspected scar dehiscence. There was one perinatal mortality in the present studydue to scar rupture.

To compare the results with other studies, Granovsky G et al reported in labor cesarean rate with epidural was $8.7 \%$, uterine rupture rate was $0.4 \%$ compared whereas in this study the repeat cesarean rate was $18 \%$ and uterine rupture was $2 \%$ ( 1 case). ${ }^{7}$

In another study by Shmueli $\mathrm{A}$ et al, where the association between epidural anesthesia and mode of delivery in TOLAC was studied showed that $12.9 \%$ incidence of repeat cesarean delivery, the indication being abnormal fetal heart tracings in $6.5 \%$, and $6.6 \%$ of babies had NICU admission, compared to $18 \%$ repeat cesarean section and $12 \%$ had NICU admission in this study. ${ }^{21}$

The limitation of the study lies in the fact that the study was carried out in a tertiary care centre, where there is adequate manpower to supervise each delivery, reducing complication rates of TOLAC. The other limitation in this study is that the sample size is small and also the present study is done in single center. A multi-centric study might be able to give a holistic picture.

\section{CONCLUSION}

With the application of epidural analgesia on attempted vaginal delivery in this study patients with a previous caesarean birth, authors were able to reduce this study caesarean delivery rate for this population alone by $18 \%$. In summary, the benefits associated with a trial of labor in the patient with a prior caesarean birth far outweigh the risks. The policy of "once a caesarean section, always a caesarean section" should be abandoned.

Therefore, in this study authors have reported that the use of epidural anaesthesia has enhanced the success of vaginal delivery in women undergoing a trial of labor following an earlier caesarean section.

Funding: No funding sources

Conflict of interest: None declared

Ethical approval: The study was approved by the Institutional Ethics Committee

\section{REFERENCES}

1. Royal College of Obstetricians and Gynaecologists (RCOG). Birth after previous caesarean section. Green-Top Guideline No. 45 London: RCOG; 2007. Available at: https://www.rcog.org.uk/en/guidelinesresearch-services/guidelines/gtg 45\%. Accessed on $10^{\text {th }}$ April 2019.

2. American College of Obstetricians and Gynecologists (ACOG). Vaginal birth after previous cesarean delivery. Washington, DC: ACOG, 2010. Available at: http://dx.doi.org/10.1097/AOG.0b013e3181eeb251. Accessed on $10^{\text {th }}$ April 2019.

3. World Health Organization. Appropriate technology for birth. Lancet. 1985;2:436-7.

4. MacDorman M, Declercq E, Menacker F. Recent trends and patterns in cesarean and vaginal birth after cesarean (VBAC) deliveries in the United States. Clin Perinatol. 2011;38:179-92.

5. Homer CS, Johnston R, Foureur MJ. Birth after caesarean section: changes over a nine-year period in one Australian state. Midwifery. 2011;27:165-9.

6. Black C, Kaye J, Jick H. Cesarean delivery in the United Kingdom: time trends in the general practice research database. Obstet Gynecol. 2005;106:151-5.

7. Grisaru-Granovsky S, Bas-Lando M, Drukker L, Haouzi F, Farkash R, Samueloff A, et al. Epidural analgesia at trial of labor after cesarean (TOLAC): A significant adjunct to successful vaginal birth after cesarean (VBAC). J Perinat Med. 2018;46(3):261-9

8. American College of Obstetricians and Gynecologists (ACOG): ACOG Practice Bulletin: vaginal birth after previous cesarean delivery: Clinical management guidelines. Int $\mathbf{J}$ Gynecol Obstet. 2004;54:197-204.

9. Khotaba S, Volfson M, Tarazova L, Odeh M, Barenboym R, Fait V, et al. Induction of labour in women with previous cesarean section using the double balloon device. Acta Obstet Gynecol Scand. 2001;80:1041-2.

10. Zeteroglu S, Ustun Y, Engin-Ustun Y, Sahin HG, Kamaci M. Eight years' experience of uterine rupture cases. J Obstet Gynaecol. 2005;25:458-61. 
11. Kayani SI, Alfirevic Z. Uterine rupture after induction of labor in women with PCS. BJOG. 2005; $112: 451$.

12. McDonagh MS, Osterweil P, Guise JM. The benefits and risks of inducing labour in patients with prior caesarean delivery: a systematic review. BJOG. 2005;112:1007-15.

13. Hassan A. Trial of scar and VBAC. J Ayub Med Coll Abbottabad. 2005;17:57.

14. Turner MJ. Delivery after one previous cesarean section. Am J Obstet Gynecol. 1997;176:741-4.

15. Zeteroglu S, Ustun Y, Engin-Ustun Y, Sahin HG, Kamaci M. Eight years' experience of uterine rupture cases. J Obstet Gynaecol. 2005;25:458-61.

16. McDonagh MS, Osterweil P, Guise JM. The benefits and risks of inducing labour in patients with prior caesarean delivery: A systematic review. BJOG. 2005;112:1007-15.

17. Dunn EA, O'Herlihy C. Comparison of maternal satisfaction following vaginal delivery after caesarean section and caesarean section after previous vaginal delivery. Eur J Obstet Gynecol Reprod Biol. 2005;121:56-60.
18. Editorial. Vaginal delivery after caesarean section. Br Med J. 2004;329:359-60.

19. Pickrell K. An inquiry into the history of cesarean section. Bull Soc Med Hist (Chicago). 1935;4:414.

20. Konefal H, Jaskot B, Czeszynska MB, Pastuszka J. Remifentanil patient-controlled analgesia for labor monitoring of newborn heart rate, blood pressure and oxygen saturation during the first 24 hours after delivery. Arch Med Sci. 2013;9(4):697-702.

21. Shmueli A, Salman L, Nassie DI, Wiznitzer A, Chen $\mathrm{R}$, Ashwal E, et al. The intriguing association between epidural anesthesia and mode of delivery among women in trial of labor after a previous cesarean delivery. Am J Obstet Gynecol. 2017;216(1):S536-7.

Cite this article as: Sundaram J, Vinoth D, Sriram M. A prospective observational study of role of epidural in trial of labour after cesarean section in view of maternal and neonatal outcome in a tertiary care hospital. Int J Reprod Contracept Obstet Gynecol 2020;9:2415-9. 